\title{
Optimal Decisions of Countries with Carbon Tax and Carbon Tariff
}

\author{
Yumei Hou ${ }^{1,2}$, Meng Jia ${ }^{1}$, Xin Tian ${ }^{3,4^{*}}$, Fangfang $\mathrm{Wei}^{1}$, Kun Wei ${ }^{2}$ \\ ${ }^{1}$ Yanshan University, College of Economics and Management (China) \\ ${ }^{2}$ The Postdoctoral Innovation Practice Base, The First Hospital of Qinhuangdao (China) \\ ${ }^{3}$ Key Laboratory of Big Data Mining and Knowledge Management, Chinese Academy of Sciences (China) \\ ${ }^{4}$ Chinese Academy of Sciences, Research Center on Fictitious Economy and Data Science (China) \\ bym@ysu.edu.cn,240578259@qq.com,*Corresponding author: tianx@ucas.ac.cn,491884795@qq.com,weikun@medmail.com.cn
}

\section{Abstract:}

Purpose: Reducing carbon emission has been the core problem of controlling global warming and climate deterioration recently. This paper focuses on the optimal carbon taxation policy levied by countries and the impact on firms' optimal production decisions.

Design/methodology/approach: This paper uses a two-stage game theory model to analyze the impact of carbon tariff and tax. Numerical simulation is used to supplement the theoretical analysis.

Findings: Results derived from the paper indicate that the demand in an unstable market is significantly affected by environmental damage level. Carbon tariff is a policy-oriented tax while the carbon tax is a market-oriented one. Comprehensive carbon taxation policy benefit developed countries and basic policy is more suitable for developing countries.

Research limitations/implications: In this research, we do not consider random demand and asymmetric information, which may not well suited the reality.

Originality/value: This work provides a different perspective in analyzing the impact of carbon tax and tariff. It is the first study to consider two consuming market and the strategic 
game between two countries. Different international status of countries considered in the paper is also a unique point.

Keywords: carbon tax, carbon tariff, leader-follower game, social welfare

\section{Introduction}

Global warming has gained increasing attentions over the past few decades. Dealing with the climate change, especially reducing greenhouse gas ( $G H G)$, has become huge challenge to human. It is well known that the carbon dioxide emitted by the production and transport activities is the main GHG to cause global warming (Song \& Leng, 2012). Consequently, reducing carbon emission has been the core problem of controlling global warming.

As reported by the Worldwatch Institute, in order to avoid the most catastrophic effects of climate change, the carbon emission all over the world have to drop to near zero by 2050 . Therefore, many countries and organizations advocate to all kinds of regulations and policies to reduce the carbon emission, of which carbon tax and "Cap-and-Trade" (C\&T) are regarded as two most efficient ways. Particularly, C\&T is a market-based policy, while carbon tax is an incentive-based policy for controlling carbon emission (He, Wang \& Wang, 2012).

Because of the financial crisis erupted in 2008, countries seek ways to shift the crisis, of which slight trade protectionism mitigates to some extent the economic depression. Tax policy, especially tariff on importers, has been an effective and reasonable way of trade protection. Currently, carbon tax has been a mainly used measure in developed countries due to its simplicity and capability to indicate carbon price immediately (Avi-Yonah \& Uhlmann, 2009). Developed countries ask for extending emission-reduction regulations to the whole world, especially to developing countries. Specifically, developed countries with low-emission level declare to implement carbon tariff on imported products from the high-emission countries, which forced developing countries to seek for ways to mitigate the negative effects on international trade.

According to the reports of Carbon Tax Center, a tax on carbon pollution will create broad incentives to encourage the decision-makers to reduce carbon emission. So carbon tax policies, including carbon tax and carbon tariff, and their implementation becomes hot topic nowadays. Therefore, a lot of scholars in the world focus on the study on the methods of using carbon tax and carbon tariff policies properly to reduce the carbon emission.

The literature on carbon emission regulations is very rich. In the early times, scholars mainly focus on the availability of different carbon policies. He et al. (2012) summarized the comparison between carbon tax and C\&T and gave a brief summary about the advantages and 
disadvantages of both two policies. Of all the carbon taxation policies, Border Carbon Adjustment (BCAs) and Border Tax Adjustment (BTAs) have been widely discussed. Research by Burniaux, Chateau and Duval (2013) analyzed the effects of BTA (border tax adjustment) using a global recursive-dynamic general equilibrium model. They found BTAs are an effective way of reducing carbon leakage if there is only a small coalition of acting countries. Burniaux et al. also pointed out that BTAs entail small welfare losses as a world level. Research by Eyland and Zaccour $(2012$, 2014) used a duopoly model composed of two different governments and their respective firms. They found that a BTA parameter of 0.5 yields the highest total welfare and can increase its acceptance within the World Trade Organization (WTO).

As to carbon tariff, research by Yu (2012) pointed that under the circumstance that developed countries may levy carbon tariff unilaterally in the near future, developing countries like China have to prepare for the potential challenge by using tactical and political approaches. Research by Wang, Wang, Dang and Wang (2012)used game theory to study the effect of carbon tariff on importers into the US. They found that introducing carbon tariff will reduce developing countries' exports to the US market and increase the developed countries' welfare. But their work didn't take environmental issues into consideration. Some researchers also carried debates on the size motivated BTA on world trade and welfare (Dong \& Walley, 2012).

Empirical studies were carried out to reveal the impact of carbon tax on industries and society. Research by Lin and Li (2011) comprehensively estimated the real mitigation effects of the five north European countries who were the first adopters of carbon tax. They found that mitigation effect of carbon tax differs from country to country. For example, the carbon tax on Finland actually exerts a negative and significant impact on $\mathrm{CO}_{2}$ emission. In addition, research by Hübler (2012) found that the mitigation effect of carbon tariff on emission appears small through analyze China's commodities trade by the CGE model. Besides, many recent climatepolicy proposals contain provisions for carbon tariff, such as the Waxman-Markey Bill and the Kerry-Boxer in the US, the revised directive of the EU ETS and so on (Springmann, 2012).

Above all, research in carbon tariff has two mainly limitations. Firstly, most of the research used CGE model, which can only reflect the unilateral impact of carbon tariff and carbon tax on countries and firms, but not the strategic game between the two countries and two firms. Secondly, all of the literatures we mentioned have only considered one consuming market, which also cannot simulate the real situation. In our paper, We provide a more comprehensive research to evaluate the impact of carbon tax and tariff on firms and social welfare based on Eyland and Zaccour (2014), which is one of the first studies to consider carbon tariff in a strategic context. Both foreign and home market are considered in our model, which is different with Eyland and Zaccour (2014). 
It is well known that some European countries like Denmark have already started levying domestic carbon tax. Recently, the EU is going to levy carbon tariff on other countries. Based on the background, this paper aims at the optimal taxation policy for countries under current carbon taxation scenes by a two-stage leader-follower game model. By analyzing the impact of comprehensive taxation policy, which has both domestic carbon tax and carbon tariff, the optimal social welfare for countries and the optimal profit for firms are given in the paper. These comprise the first part of our work. Our research holds a new perspective which considers two consuming markets located in two countries respectively. Furthermore, this research puts environmental issues in a momentous position. The purpose of this study focuses on the overall taxation policies, including domestic carbon tax and carbon tariff taken by other countries, but not on the adjustment of border tax. Whereas in fact, the combined effect of domestic carbon tax and carbon tariff is similar to that of border tax adjustment (BTA). The comprehensive taxation policy given in this paper implements easily and matches present situation better. For simplicity, domestic carbon tax is denoted as carbon tax and carbon tariff is denoted as tariff in our paper.

The remainder of the paper is organized as follows. In section 2, we introduce the modeling of our paper. Four different taxation scenarios are presented in section 3 . In section 4 , the comparisons of the decision-makings of countries and firms are focused. Furthermore, the numerical analyses are made to confirm and supplement the comparisons. Finally, remarkable conclusions and discussions on possible extensions are summarized in section 5.

\section{Model Formulation}

We consider two oligopoly firms (denoted by firm $x$ and $y$ ) located in their own country respectively produce a homogeneous good. Each country maximizes her own social welfare by levying a taxation policy, i.e., a carbon tax on domestic firms and a tariff on importers. The carbon tax may either be positive or be negative. Positive carbon tax is a kind of punitive measure on firms for their damage to the environment and negative carbon tax is a subsidy on firms for their achievement of environmental protection. According to the taxation policy levied by country $x$ and country $y$, each oligopoly firm make her decisions on the optimal output and optimal sales quantities in domestic and abroad to maximize the profit.

We model a sequential non-cooperative game with the countries as the leader and the firms as the follower The countries first declare the carbon tax rate, then the firms decide their optimal output and sales decisions. The optimal taxation policy (either carbon tax or tariff or both) adopted by countries force the firms to conduct energy conservation and emission reduction. 
We adopt the inverse-linear demand, as expressed by Equation (1):

$$
p_{i}=a_{i}-b_{i} q_{i}, i=x, y
$$

Where $p_{i}$ is the price of the good and $a_{i}$ and $b_{i}$ are the demand parameters of market $i$. It is known that $b_{i}$ indicates the stability of markets. Let $c_{i}$ be the production cost of the firm, which satisfies the inequality $0<c_{i}<a_{i}$. The more a firm invests in emission reduction, the higher the production costs and the lower emission per unit product she has.

Take country $x$ and firm $x$ as examples. The carbon emission emitted by unit product $x$ is denoted by $d_{x}$. For modeling, country $x$ decides carbon tax rate $t_{x}^{b}$ (carbon tax) or $t_{x}$ (carbon tariff) firstly. Then firm $x$ and $y$ make total output (denoted by $q_{x}$ and $q_{y}$ ) and the sales quantity decisions domestically and abroad, denoted by $h_{x x}$ and $e_{x y}, h_{y y}$ and $e_{y x}$ respectively.

So we have total output of firm $x$ and total demand of market $x$ (Equation 2):

$$
\left\{\begin{array}{l}
q_{x}=h_{x x}+e_{x y} \\
D_{x}=h_{x x}+e_{y x}
\end{array}\right.
$$

Tax fees paid by firm $x$ (denoted by $T_{x}$ ) includes two parts, carbon tax paid to country $x$ and tariff paid to country $y$, i.e., $T_{x}=t_{x}^{b} d_{x} h_{x x}+t_{y} d_{x} e_{x y}$.

Accordingly, the income of firm $x$ is composed of two parts, which include the sales revenues in home and abroad; the $x$ firm's cost has two parts also, which include the production cost and the tax fees. So the profit function is given by Equation (3):

$$
\pi_{x}=\left[a_{x}-b_{x}\left(h_{x x}+e_{y x}\right)\right] \cdot h_{x x}+\left[a_{y}-b_{y}\left(h_{y y}+e_{x y}\right)\right] \cdot \mathrm{e}_{x y}-\mathrm{c}_{x}\left(h_{x x}+e_{x y}\right)-t_{x}^{b} d_{x} h_{x x}-t_{y} d_{x} e_{x y}
$$

The social welfare of country $x$ (denoted by $R_{x}$ ) is constituted of four parts: the consumer surplus of market $x\left(C S_{x}\right)$, profit of firm $x\left(\pi_{x}\right)$, carbon tax paid by firm $x$ and $y\left(T R_{x}\right)$, and the cost of the environmental damage by firm $x$ during her production process $\left(L_{x}\right)$, i.e.,

$$
R_{x}=C S_{x}+\pi_{x}+T R x-L_{x}
$$

Where $T R_{x}=t_{x}^{b} d_{x} h_{x x}+t_{y} d_{x} e_{x y}, L_{x}=l_{x} d_{x}\left(h_{x x}+e_{x y}\right)$, and $l_{x}$ indicates the environmental damage cost parameter. Given the linear specification for the inverse demand, the consumer surplus in country $x$ can be easily established, i.e., $C S_{x}=b_{x}\left(h_{x x}+e_{y x}\right)^{2} / 2$.

Nothing that the total cost of the market $x$ is $c_{x}+l_{x} d_{x}$ the upper bound of the total cost of the market $x$ is $a_{x}$ and the lower bound of the total cost of the market $x$ is 0 . So the following inequality (cost constraint). 
Nothing that the total cost of the market $x$ is $c_{x}+l_{x} d_{x}$ the upper bound of the total cost of the market $x$ is $a^{x}$ and the lower bound of the total cost of the market $x$ is 0 . So the following inequality (cost constraint) $0<c_{x}+l_{x} \cdot d_{x}<a_{x}$ holds.

\section{Four Taxation Policy Scenarios}

In this section, four scenarios which are most suitable for the reality are focused. For brevity, in the subsequent sections, we let $\mathbf{D}$ denote to the scenario that a country levy carbon tax on domestic firms and $\mathbf{I}$ denotes to the scenario that a country levy tariff on import firms. For convenience and brevity when we make shorten notations, the carbon tax (D) is always in front of tariff (I). Moreover, the policy of country $x$ is always in front of the policy of country $y$. For instance, the DIDI scenario refers to that two countries both levy carbon taxes and tariffs and the DID scenario means that country $x$ levy carbon tax and tariff while country $y$ just levy carbon tax.

\subsection{The DIDI Scenario}

In this scenario, both countries levy carbon tax and tariff on firms, i.e., (and $t_{x}^{b} \neq 0, t_{y}^{b} \neq 0$ and $t_{x}>0, t_{y}>0$ ). To determine the Stackelberg equilibrium, the reverse recursive method is used. In order to prove the existence of the Stackelberg equilibrium, Hessian matrix is calculated. The Hessian matrix of the $x$ firm's profit function (denoted by $H\left(\pi_{x}\right)$ ) is given by Equation (5):

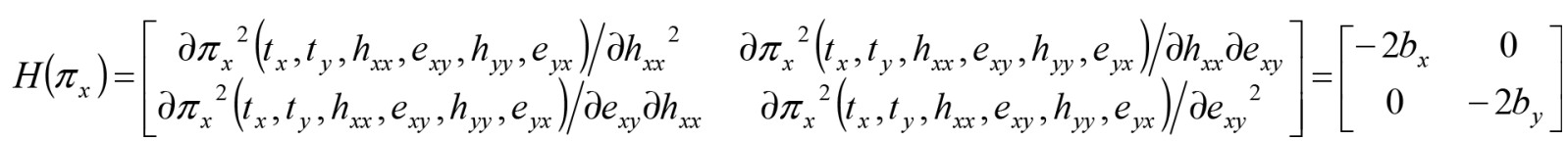

Because the Hessian matrix is negative definite, the Stackelberg equilibrium must exist. Therefore, the optimal sales decisions of the $x$ firm satisfied the first order conditions as follows:

$$
\left\{\begin{array}{l}
\partial \pi_{x} / \partial h_{x x}=a_{x}-2 b_{x} h_{x x}-b_{x} e_{y x}-c_{x}-t_{x}^{b} d_{x}=0 \\
\partial \pi_{x} / \partial e_{x y}=a_{y}-b_{y} h_{y y}-2 b_{y} e_{x y}-c_{x}-t_{y} d_{x}=0
\end{array}\right.
$$


Accordingly, we have the following reaction functions (Equation 7):

$$
\left\{\begin{array}{l}
h_{x x}\left(t_{x}^{*}, t_{x}^{b^{*}}\right)=\left(a_{x}-2 c_{x}+c_{y}+t_{x}^{*} d_{y}-2 t_{x}^{b^{*}} d_{x}\right) / 3 b_{x} \\
e_{x y}\left(t_{y}^{*}, t_{y}^{b^{*}}\right)=\left(a_{y}-2 c_{x}+c_{y}-2 t_{y}^{*} d_{x}+t_{y}^{b^{*}} d_{y}\right) / 3 b_{y} \\
h_{y y}\left(t_{y}^{*}, t_{y}^{b^{*}}\right)=\left(a_{y}-2 c_{y}+c_{x}+t_{y}^{*} d_{x}-2 t_{y}^{b^{*}} d_{y}\right) / 3 b_{y} \\
e_{y x}\left(t_{x}^{*}, t_{x}^{b^{*}}\right)=\left(a_{x}-2 c_{y}+c_{x}-2 t_{x}^{*} d_{y}+t_{x}^{b^{*}} d_{x}\right) / 3 b_{x}
\end{array}\right.
$$

A simple analysis of the above reaction functions indicates that the effects of tax in the same market on two firms show a different trend, which can be seen from the following characterization (Equation 8):

$$
\left\{\begin{array} { l } 
{ \partial h _ { x x } / \partial t _ { x } ^ { * } > 0 , \partial h _ { x x } / \partial t _ { x } ^ { b ^ { * } } < 0 } \\
{ \partial e _ { y x } / \partial t _ { x } ^ { * } < 0 , \partial e _ { y x } / \partial t _ { x } ^ { b ^ { * } } > 0 }
\end{array} \left\{\begin{array}{l}
\partial h_{y y} / \partial t_{y}^{*}>0, \partial h_{y y} / \partial t_{y}^{b^{*}}<0 \\
\partial e_{x y} / \partial t_{y}^{*}<0, \partial e_{x y} / \partial t_{y}^{b^{*}}>0
\end{array}\right.\right.
$$

Equation (8) shows that the higher the carbon tax rate is, the fewer sales quantity the firm will allocate in domestic market and the more she will allocate in abroad market, whereas the higher the tariff is, the more sales quantity the firm will allocate in domestic and the fewer she will allocate in abroad market. The impact of tax on decisions depends on the overall effect of the two kinds of taxation. So we have the following proposition:

Proposition 1. The carbon tax will hurt domestic sales quantity and enhance import sales quantity, while the tariff will hurt import sales quantity and enhance domestic sales quantity.

Proposition 1 shows that if one country raises tariff, the import and export trade between the two countries will be hurt. From the perspective of the other country, she may force her own firm to reduce export quantity to the country and encourage she to conduct export trade with any other countries. And this conclusion is in consistent with Eyland and Zaccour (2014).

Combining Equations (4 and 7), the unique Stackelberg equilibrium of the DIDI scenario are given by Equations. ( 9 and 10):

$$
\left\{\begin{array}{l}
h_{x x}^{*}=\left(2 a_{x}-3 c_{x}+c_{y}-3 l_{x} d_{x}\right) / 2 b_{x} \\
e_{x y}^{*}=\left(c_{y}-c_{x}+l_{y} d_{y}\right) / 2 b_{y} \\
h_{y y}^{*}=\left(2 a_{y}-3 c_{y}+c_{x}-3 l_{y} d_{y}\right) / 2 b_{y} \\
e_{y x}^{*}=\left(c_{x}-c_{y}+l_{x} d_{x}\right) / 2 b_{x}
\end{array}\right.
$$




$$
\left\{\begin{array}{l}
t_{x}^{*}=\left(l_{x} d_{x}+c_{x}-c_{y}\right) / 2 d_{y} \\
t_{x}^{b^{*}}=\left(-2 a_{x}+3 c_{x}-c_{y}+5 l_{x} d_{x}\right) / 2 d_{x} \\
t_{y}^{*}=\left(l_{y} d_{y}+c_{y}-c_{x}\right) / 2 d_{x} \\
t_{y}^{b^{*}}=\left(-2 a_{y}+3 c_{y}-c_{x}+5 l_{y} d_{y}\right) / 2 d_{y}
\end{array}\right.
$$

According to Equation (9), we have proposition 2.

Proposition 2. Total output of a firm is decreasing in his production cost. Market demand is decreasing in its environmental damage.

Combining Equations ( 2 and 9), we can see that if the firms' production cost increase, they will reduce their output. It is because that the more the firms produce, the more loss they may suffer as the production cost changes higher. In fact, if a firm invests more on emission reduction, she will have a higher production cost but a lower emission per unit product. Therefore, in order to get the maximum firm profit, a firm must take measures to balance the costs, i.e., she should reduce emission as much as possible while keeping the production cost at an acceptable value.

The total demand of market $x$ is given by Equation (11):

$$
D_{x}=h_{x x}^{*}+e_{y x}^{*}=\left(a_{x}-c_{x}-l_{x} d_{x}\right) / b_{x}
$$

which has nothing to do with country $y$ and firm $y$ intuitively. With the increase of environmental damage, market demand decreases more because of price sensitive parameter $b_{x}$.

Corollary 1. Countries with unstable market should pay more attention to environmental damage issues.

From Equation (11), we can see that for the same environmental damage level, unstable market with lower $b_{i}$ will suffer more negative influence caused by environmental damage. Therefore, in order to stabilize market demand, countries should pay more attention to environmental damage issues.

Corollary 2. Carbon tariff is mainly used to protect own firms; carbon tax is mainly used to control environmental damage.

Results show that the optimal carbon tariff $t_{x}{ }^{*}$ increases in the carbon emission per unit production produced by $x$ firm $\left(d_{x}\right)$ and decreases in the carbon emission per unit production 
produced by $y$ firm $d_{y}$. Consumers are more aware of environmental issues now, i.e., they prefer green products. Thus products with higher environmental damage level will have less competitiveness. In order to protect domestic firms and increase the market entry threshold of the import firms, countries with high-polluted firms are likely to increase tariff. In addition, the optimal carbon tax rate $t_{x}{ }^{b^{*}}$ and $t_{y}{ }^{b^{*}}$ indicate that environmental damage level plays a more important role decided the optimal carbon tariff than that one decided the optimal carbon tax rate.

From what has been discussed above the firms' profit function and social welfare can also described by Equations (12 and 13):

$$
\begin{gathered}
\left\{\begin{array}{l}
\pi_{x}^{*}=\left(2 a_{x}-3 c_{x}+c_{y}-3 l_{x} d_{x}\right)^{2} / 4 b_{x}+\left(c_{y}-c_{x}+l_{y} d_{y}\right)^{2} / 4 b_{y} \\
\pi_{y}^{*}=\left(2 a_{y}-3 c_{y}+c_{x}-3 l_{y} d_{y}\right)^{2} / 4 b_{y}+\left(c_{x}-c_{y}+l_{x} d_{x}\right)^{2} / 4 b_{x}
\end{array}\right. \\
\left\{\begin{array}{l}
R_{x}^{*}=\left(a_{x}-c_{x}-l_{x} d_{x}\right)^{2} / 2 b_{x}+\left(c_{y}-c_{x}+l_{y} d_{y}\right)^{2} / 4 b_{y}+\left(c_{x}-c_{y}+l_{x} d_{x}\right)^{2} / 4 b_{x}-l_{x} d_{x}\left(c_{y}-c_{x}+l_{y} d_{y}\right) / 2 b_{y} \\
R_{y}^{*}=\left(a_{y}-c_{y}-l_{y} d_{y}\right)^{2} / 2 b_{y}+\left(c_{x}-c_{y}+l_{x} d_{x}\right)^{2} / 4 b_{x}+\left(c_{y}-c_{x}+l_{y} d_{y}\right)^{2} / 4 b_{y}-l_{y} d_{y}\left(c_{x}-c_{y}+l_{x} d_{x}\right) / 2 b_{x}
\end{array}\right.
\end{gathered}
$$

Under this taxation policy scenario, firm profit and social welfare are influenced by every part of the trade between the two countries.

Proposition 3. Firm profit increase with the other firm's production cost and environmental damage cost. Meanwhile, it decrease in its own production cost and environmental damage cost.

From proposition 3 the production cost and environmental damage cost jointly affect on the firm's profit are obtain. To arrive the balance and achieve the firm's profit maximized firms must choose the cost of production and environment damaged cost.

Results obtained above have some limitations. All the sale quantities and firm profits should be positive, which could ensure the firms' willingness to produce. Under the limitations, we know that the tariff of DIDI scenario is positive but the carbon tax depends on the firms' production costs and the environment damage cost of her own country. Clearly, if the environmental damage cost is higher enough, both countries will tax their firms and their social welfare are negative. Note that this limitations mentioned also apply to the following scenarios.

In order to determine the equilibrium of other scenarios, we still follow the steps used in DIDI scenario, where we only change the tax which countries levied on firms. In addition, the maximization of the firms' profits and social welfare are similar to that of DIDI scenario. So we omit the details and just give the results obtained on each scenario in the following parts. 


\subsection{DD Scenario}

Both countries only levy carbon tax on domestic firms separately, i.e., $\left(t_{x}^{b} \neq 0, t_{y}^{b} \neq 0\right)$. The decisions of firms and countries can be given by Equations (14-17):

$$
\begin{aligned}
& \left\{\begin{array}{l}
h_{x x}^{*}=\left(3 a_{x}-4 c_{x}+c_{y}-4 l_{x} d_{x}\right) / 3 b_{x} \\
e_{x y}^{*}=2\left(c_{y}-c_{x}+l_{y} d_{y}\right) / 3 b_{y} \\
h_{y y}^{*}=\left(3 a_{y}-4 c_{y}+c_{x}-4 l_{y} d_{y}\right) / 3 b_{y} \\
e_{y x}^{*}=2\left(c_{x}-c_{y}+l_{x} d_{x}\right) / 3 b_{x}
\end{array}\right. \\
& \left\{\begin{array}{l}
t_{x}^{b^{*}}=\left(-a_{x}+c_{x}+2 l_{x} d_{x}\right) / d_{x} \\
t_{y}^{b^{*}}=\left(-a_{y}+c_{y}+2 l_{y} d_{y}\right) / d_{y}
\end{array}\right. \\
& \left\{\begin{array}{l}
\pi_{x}^{*}=\left(3 a_{x}-4 c_{x}+c_{y}-4 l_{x} d_{x}\right)^{2} / 9 b_{x}+4\left(c_{y}-c_{x}+l_{y} d_{y}\right)^{2} / 9 b_{y} \\
\pi_{y}^{*}=\left(3 a_{y}-4 c_{y}+c_{x}-4 l_{y} d_{y}\right)^{2} / 9 b_{y}+4\left(c_{x}-c_{y}+l_{x} d_{x}\right)^{2} / 9 b_{x}
\end{array}\right. \\
& \int R_{x}^{*}=\left(3 a_{x}-2 c_{x}-c_{y}-2 l_{x} d_{x}\right)^{2} / 81 b_{x}+\left(-a_{x}+2 l_{x} d_{x}+c_{x}\right)\left(3 a_{x}-4 c_{x}+c_{y}-4 l_{x} d_{x}\right) / 3 b_{x} \\
& +\left(3 a_{x}-4 c_{x}+c_{y}-11 l_{x} d_{x} / 2\right)^{2} / 9 b_{x}+\left(2 c_{y}-2 c_{x}+2 l_{y} d_{y}-3 l_{x} d_{x} / 2\right)^{2} / 9 b_{y}-l_{x}^{2} d_{x}^{2} / 4 b_{x}-l_{x}^{2} d_{x}^{2} / 4 b_{y} \\
& \left\{R_{y}^{*}=\left(3 a_{y}-2 c_{y}-c_{x}-2 l_{y} d_{y}\right)^{2} / 81 b_{y}+\left(-a_{y}+2 l_{y} d_{y}+c_{y}\right)\left(3 a_{y}-4 c_{y}+c_{x}-4 l_{y} d_{y}\right) / 3 b_{y}\right. \\
& +\left(3 a_{y}-4 c_{y}+c_{x}-11 l_{y} d_{y} / 2\right)^{2} / 9 b_{y}+\left(2 c_{x}-2 c_{y}+2 l_{x} d_{x}-3 l_{y} d_{y} / 2\right)^{2} / 9 b_{x}-l_{y}{ }^{2} d_{y}{ }^{2} / 4 b_{y}-l_{y}{ }^{2} d_{y}{ }^{2} / 4 b_{x}
\end{aligned}
$$

To briefly compare the results obtained in the two scenarios, we find that the sales quantity and total output of scenario DD are higher than that of scenario DIDI. Thus firm profit is obviously higher in scenario DD than in DIDI. However, social welfare is too complicated to compare from Equation (17). Therefore, the two firms will prefer the DD taxation policy, but the countries' preference needs further investigation. Moreover, in scenario DD, optimal carbon $\operatorname{tax} t_{x}^{b^{*}}\left(t_{y}^{b^{*}}\right)$ is independent on other country and import firm.

\subsection{Scenario}

In this scenario, only country $x$ has carbon tax policies, including carbon tax on domestic firm and tariff on import firm, i.e., $\left(t_{x}^{b}>0\right.$ and $\left.t_{x} \neq 0\right)$. The decisions of firms and countries are described by Equstions (18-21):

$$
\left\{\begin{array}{l}
h_{x x}^{*}=\left(2 a_{x}-3 c_{x}+c_{y}-3 l_{x} d_{x}\right) / 2 b_{x} \\
e_{x y}^{*}=\left(a_{y}-2 c_{x}+c_{y}\right) / 3 b_{y} \\
h_{y y}^{*}=\left(a_{y}-2 c_{y}+c_{x}\right) / 3 b_{y} \\
e_{y x}^{*}=\left(c_{x}-c_{y}+l_{x} d_{x}\right) / 2 b_{x}
\end{array}\right.
$$




$$
\begin{gathered}
\left\{\begin{array}{l}
t_{x}^{*}=\left(l_{x} d_{x}+c_{x}-c_{y}\right) / 2 d_{y} \\
t_{x}^{b^{*}}=\left(-2 a_{x}+3 c_{x}-c_{y}+5 l_{x} d_{x}\right) / 2 d_{x}
\end{array}\right. \\
\left\{\begin{array}{l}
\pi_{x}^{*}=\left(2 a_{x}-3 c_{x}+c_{y}-3 l_{x} d_{x}\right)^{2} / 4 b_{x}+\left(a_{y}-2 c_{x}+c_{y}\right)^{2} / 9 b_{y} \\
\pi_{y}^{*}=\left(a_{y}-2 c_{y}+c_{x}\right)^{2} / 9 b_{y}+\left(c_{x}-c_{y}+l_{x} d_{x}\right)^{2} / 4 b_{x}
\end{array}\right. \\
\left\{\begin{array}{l}
R_{x}^{*}=\left(a_{x}-c_{x}-l_{x} d_{x}\right)^{2} / 2 b_{x}+\left(a_{y}-2 c_{x}+c_{y}\right)^{2} / 9 b_{y}+\left(l_{x} d_{x}+c_{x}-c_{y}\right)^{2} / 4 b_{x}-l_{x} d_{x}\left(a_{y}-2 c_{x}+c_{y}\right)^{2} / 3 b_{y} \\
R_{y}^{*}=\left(3 a_{y}+2 c_{y}-5 c_{x}+2 l_{y} d_{y}\right)^{2} / 162 b_{y}+\left(a_{y}+c_{x}-2 c_{y}\right)\left(a_{y}+c_{x}-2 c_{y}-3 l_{y} d_{y}\right) / 9 b_{y} \\
+\left(c_{x}-c_{y}+l_{x} d_{x}\right)\left(c_{x}-c_{y}+l_{x} d_{x}-2 l_{y} d_{y}\right) / 4 b_{x}
\end{array}\right.
\end{gathered}
$$

Proposition 4. Unilateral taxation policy cannot reach the goal of emission reduction.

Under this taxation policy, the total output and sales quantity of the firm $x$ is independent on the environmental damage level of country $y$. Sales decisions are mostly affected by the two production costs $\left(c_{x}\right.$ and $c_{y}$ ). From Equation (18), we can see that output of firm $y(x)$ decreases in her own production cost $c_{y}\left(c_{x}\right)$. So in order to maximize $y$ firm's profit she should reduce her own production cost as far as possible. Firm $x$ will not consider the environment issues seriously. Generally, countries without carbon taxation policy are heavy-polluting countries while most of the countries with sound carbon taxation policy can set their pollution level under control. Therefore, this unilateral carbon taxation policy cannot control firms to conduct emission reduction, especially for countries have no carbon taxation policy.

\subsection{DID Scenario}

In this scenario, the two countries both levy carbon tax on domestic, but only country $x$ has the tariff on the import firm, i.e., $\left(t_{x}>0\right.$ and $\left.t_{x}^{b} \neq 0, t_{y}^{b} \neq 0\right)$. The decisions of firms and countries are described by Equations (22-25):

$$
\begin{gathered}
\left\{\begin{array}{l}
h_{x x}^{*}=\left(2 a_{x}-3 c_{x}+c_{y}-3 l_{x} d_{x}\right) / 2 b_{x} \\
e_{x y}^{*}=2\left(c_{y}-c_{x}+l_{y} d_{y}\right) / 3 b_{y} \\
h_{y y}^{*}=\left(3 a_{y}-4 c_{y}+c_{x}-4 l_{y} d_{y}\right) / 3 b_{y} \\
e_{y x}^{*}=\left(c_{x}-c_{y}+l_{x} d_{x}\right) / 2 b_{x}
\end{array}\right. \\
\left\{\begin{array}{l}
t_{x}^{*}=\left(l_{x} d_{x}+c_{x}-c_{y}\right) / 2 d_{y} \\
t_{x}^{b^{*}}=\left(-2 a_{x}+3 c_{x}-c_{y}+5 l_{x} d_{x}\right) / 2 d_{x} \\
t_{y}^{b^{*}}=\left(-a_{y}+c_{y}+2 l_{y} d_{y}\right) / d_{y}
\end{array}\right.
\end{gathered}
$$




$$
\begin{gathered}
\left\{\begin{array}{l}
\pi_{x}^{*}=\left(2 a_{x}-3 c_{x}+c_{y}-3 l_{x} d_{x}\right)^{2} / 4 b_{x}+4\left(c_{y}-c_{x}+l_{y} d_{y}\right)^{2} / 9 b_{y} \\
\pi_{y}^{*}=\left(3 a_{y}-4 c_{y}+c_{x}-4 l_{y} d_{y}\right)^{2} / 9 b_{y}+\left(c_{x}-c_{y}+l_{x} d_{x}\right)^{2} / 4 b_{x}
\end{array}\right. \\
\left\{\begin{array}{r}
R_{x}^{*}=\left(a_{x}-c_{x}-l_{x} d_{x}\right)^{2} / 2 b_{x}+4\left(c_{y}-c_{x}+2 l_{y} d_{y}\right)^{2} / 9 b_{y}+\left(l_{x} d_{x}+c_{x}-c_{y}\right)^{2} / 4 b_{x}-4 l_{x} d_{x}\left(c_{y}-c_{x}+l_{y} d_{y}\right)^{2} / 3 b_{y} \\
R_{y}^{*}=\left(3 a_{y}-2 c_{y}-c_{x}-2 l_{y} d_{y}\right)^{2} / 18 b_{y}+\left(l_{x} d_{x}+c_{x}-c_{y}\right)^{2} / 4 b_{x}-l_{y} d_{y}\left(l_{x} d_{x}+c_{x}-c_{y}\right) / 2 b_{x} \\
+\left(3 a_{y}+c_{x}-4 c_{y}-4 l_{y} d_{y}\right)\left(c_{x}-c_{y}-l_{y} d_{y}\right) / 9 b_{y}
\end{array}\right.
\end{gathered}
$$

To synthesize the four scenarios, the optimal carbon tariff is independent of the demand. Therefore, tariff is an indicator of policy, which is not affected by market and demand fluctuation. But carbon tax is affected by both domestic market and demand parameter.

\section{The Decision-Makings Under Different Scenarios}

In the previous section the carbon tax policy in every scenarios is discussed. This section we mainly focus on consumer surplus and environmental damage level of the social welfare function Equation (4). In addition, consumer surplus and environmental damage level have different effect on the social welfare in different scenarios. To light on the insensitive analysis on the firm profit and social welfare numerical examples are given in this part.

\subsection{The Comparative Analysis}

Now a crosswise comparisons among the four taxation scenarios are conducted. The real situation is divided into two scenarios in our analysis. One is the decision-making of twodeveloped-country scenario; the other is the decision-making of developed-developing country scenario.

\subsubsection{The Decision-Making of Two-Developed-Country Scenario}

In this case, two developed countries such as U.S. and Denmark where carbon taxation policies have played an important role in reducing emissions are considered. Those countries' taxation policies are the same as those in scenario DD. Moreover, certain country proposes that tariff should be introduced to protect domestic goods and control GHG emissions. Therefore, our next task is to investigate whether carbon tariff will benefit the two countries or not. 
Because the comparative results of the two countries are symmetrical, for simplicity, we take country $x$ as an example to analyze. Combining Equations (4, 9, 14), he difference of environmental damage cost between the two scenarios is given by Equation (26):

$$
L_{x}^{D I D I}-L_{x}^{D D}=l_{x} d_{x}\left(\left(c_{y}-c_{x}-l_{x} d_{x}\right) / b_{x}+\left(c_{x}-c_{y}-l_{y} d_{y}\right) / b_{y}\right)
$$

For the two developed countries, their markets maturities are almost at the same level if $b_{x}=b_{y}$ holds. Under this assumption, Equation (26) is always negative, which means that levying tariff can indeed reduce emission and decrease the harm to environment. This is beneficial to the whole country's social welfare. But the reduction of emission is mainly due to the decrease of production quantity, which at the same time will influence consumer surplus. So we have (Equation 27):

$$
C S_{x}^{D I D I}-C S_{x}^{D D}=-\left(6 a_{x}-5 c_{x}-c_{y}-5 l_{x} d_{x}\right)\left(c_{x}-c_{y}+l_{x} d_{x}\right) / 18 b_{x}
$$

Under the cost constraint and the limitation that the production quantities (Equation 14) should be positive, $c_{x}-c_{y}+l_{x} d_{x}>0$ and $3 a_{x}-4 c_{x}+c_{y}-4 l_{x} d_{x}>0$ hold. These indicate that $C S_{x}^{D I D I}-C S_{x}^{D D}$ is negative. So the consumer surplus is hurt if countries start to levy tariff. In addition, we have analyzed in 3.2 that the sales quantity, total output and firm profit of scenario DD are higher than that of scenario DIDI. Thus we have the following proposition.

Proposition 5. For two developed countries with carbon tax, levying tariff on import firm will result in a loss of consumer surplus but an improvement on the environment. But Firm profit and total output will be hurt.

\subsubsection{The Decision-Making of Developed-Developing Country Group}

The American Clean Energy and Security Act of 2009 stipulates that from the year 2020, the U.S. will start to impose import products' tariff on countries (China included) which do not implement carbon emission reduction.

Although there is no real carbon tariff now, it is still a worldwide trend because of the global warming and the attention to environmental issues. Therefore, how to deal with the taxation policy in developed countries is a meaningful question and worth an in-depth research for developing countries also.

In subsequence the optimal corresponding taxation strategies in developing countries are discussed.. We mainly address the effect of taxation policy on country $y$ (developing country). According to our scenario settings, it is believed that a developed country has lower product 
cost, so we have $c_{x}>c_{y}$. According to the reality, we made two comparisons in this section. One is the comparison between DI and DID scenario; the other is the comparison between DI and DIDI scenario.

The comparison between DI and DID policy is first addressed. Under this circumstance, country $x$ (the developed country) has carbon tax and tariff, country $y$ has to consider whether to levying carbon tax on domestic firms or not. Proposition 4 shows that unilateral taxation policy cannot reach the goal of emission reduction. Therefore, from the standpoint of both countries, country $y$ has to take some measures accordingly. From Equation (18) and (22), we could derive the following equation (Equation 28):

$$
L_{x}^{D I D}-L_{x}^{D I}=l_{x} d_{x}\left(c_{y}+l_{y} d_{y}-a_{y}\right) / 3 b_{y}
$$

which is obvious negative according to the cost constraint. And for country $y$, Equation (29) holds:

$$
L_{y}^{D I D}-L_{y}^{D I}=2 l_{y} d_{y}\left(a_{y}-c_{y}-2 l_{y} d_{y}\right) / 3 b_{y}
$$

which indicates that the result of this equation depends on the relationship between $a_{y}$ and $c_{y}+2 l_{y} d_{y}$. From Equation (23), it can be seen that if $t_{y}^{b}>0$, then $a_{y}<\mathrm{c}_{y}+2 l_{y} d_{y}$, the environmental damage will be reduced. If $t_{y}{ }^{b}<0$, the environmental condition will be deteriorated.

Consumer surplus of country $x\left(C S_{x}\right)$ is equal in the two scenarios, whereas the difference of country $y\left(C S_{y}\right)$ is given by Equation (30):

$$
C S_{y}^{D I D}-C S_{y}^{D I}=\left(5 a_{y}-2 c_{x}-3 c_{y}-2 l_{y} d_{y}\right)\left(a_{y}-c_{y}-2 l_{y} d_{y}\right) / 18 b_{y}
$$

According to the cost constraint $5 a_{y}-2 c_{x}-3 c_{y}-3 l_{y} d_{y}>0$, so $5 a_{y}-2 c_{x}-3 c_{y}-2 l_{y} d_{y}>0$ always holds. Therefore, the result of Equation (30) is similar to our previous analysis. If country $y$ levy carbon tax on her firms, i.e., $-a_{x}+c_{y}+2 l_{y} d_{y}>0$, consumer surplus will be hurt. If country $y$ subsidizes her firms, consumer surplus will be improved. Based on the analysis above, we have the following proposition.

Proposition 6. For a developing country in this circumstance: (i) if $a_{y}$ is big enough, she subsidize her firms, the consumer surplus will be improved while the environment will be deteriorated; (ii) if she levy carbon tax on her firms, the consumer surplus will be reduced but the environment will be improved. For developed country, the environment will always be improved. 
Proposition 6 indicates that developed countries will be pleased to see developing countries take measures, for example, levying carbon tax to control the carbon emission and environment deterioration. This indication could also be an explanation to the question why developed countries would like to force developing countries to take emission reduction measures in real-life situation.

Next, the comparison between DI and DIDI policy is presented. From Equation (9) and (18), we have the following equations (Equations 31 and 32):

$$
L_{x}^{D I D I}-L_{x}^{D I}=l_{x} d_{x}\left(c_{y}+c_{x}+3 l_{y} d_{y}-2 a_{y}\right) / 6 b_{y}
$$

and

$$
L_{y}^{D I D I}-L_{y}^{D I}=l_{x} d_{x}\left(4 a_{y}-9 l_{y} d_{y}-5 c_{y}+c_{x}\right) / 6 b_{y}
$$

It can easily be found that these two results depend on the relative value of $a_{y}$ and $c_{y}+l_{y} d_{y}$. If $a_{y}$ is big enough, then taxation policy of scenario DIDI is better for developed country for its lower environmental damage level.

As to the consumer surplus, there is no difference of country $x$ between the two scenarios. While for country $y$, Equation (33) indicates the difference between the two scenarios.

$$
C S_{y}^{D I D I}-C S_{y}^{D I}=\left(5 a_{y}-c_{x}-4 c_{y}-3 l_{y} d_{y}\right)\left(a_{y}-2 c_{y}+c_{x}-3 l_{y} d_{y}\right) / 18 b_{y}
$$

According to the cost constraint, $5 a_{y}-c_{x}-4 c_{y}-5 l_{y} d_{y}>0$ holds. Under the production quantities limitation, if $a_{y}$ is bigger enough, country $y^{\prime}$ s decisions of levying carbon tax and tariff will benefit the consumer surplus. Otherwise her consumer surplus will be hurt.

Proposition 7. For a developing country in this circumstance (i) if $a_{y}$ is big enough, her decisions of levying carbon tax and tariff will improve the consumer surplus however increase emission; (ii) if $a_{y}$ is relatively small, her decision of levying carbon tax and tariff will reduce the consumer surplus however improve the environment.

It can be seen from proposition 6 and 7 that levying carbon tax and tariff in the same time may have a complex impact on developing countries, which could either be positive or negative. Carbon taxation policy in developing countries is not so consummate. Therefore, if they start to levy carbon tax and tariff at the same time, great effort must be made to balance the impact of the two kinds of tax. This will obviously increase the difficulty of government decision-making. From what has been discussed above it is better for developing countries to impose a carbon tax first, which could also be the first step of the countries' perfection process of taxation system. 


\subsection{Numerical Results}

Since the comparison of profits and social welfare between different scenarios are too complex with analytic form, the numerical analysis is conducted in subsequence. Furthermore it is an intuitive expression for the results full analytically investigated in general case.

Without loss of generality and keep the number of simulations manageable, some bounds on the parameter are set. For every scenario, we normalize the market demand parameters $b_{x}\left(b_{x}=b_{y}\right)$ equal to 1 in order to keep the demand parameter from affecting the results. From the analysis above we can see that $a_{y}$ and $c_{y}+l_{y} d_{y}$ played an important role in every scenario analyzed above, so we like to indicate effect of the environmental damage cost parameter $l_{y}$.

\subsubsection{The Two-Developed-Country Group}

The two developed countries are almost the same in all parameters, so we set $a_{x}=a_{y}=1$; $c_{x}=c_{y}=0.1 ; d_{x}=d_{y}=0.5$. We let $l_{x}=l_{y}$ in this section to investigate the impact of $a_{y}$ and $c_{y}+l_{y} d_{y}$ on firm profit and social welfare.

Firstly, the analysis is conduct in the country $x$. Figure 1 indicates that levying tariffs will hurt firm's profit, which is accordance with the reality. It also intuitively shows that in each scenario, the increase of the damage cost leads to a lower profit of the firm and a lower social welfare of the country. Moreover, the gap between the profits is increase with the damage cost. Clearly, if the damage cost is high, government will put heavy tax and tariff on firms to control the emission.

It can be seen that levying tariff improves the social welfare of countries, which means that the gain resulting from decreased environmental damage outweighs the loss in the other components of social welfare. The gap between the two scenarios decrease in the damage cost, which indicates that the taxation policy will be less effective if the damage cost is extremely high. In such circumstance, it is better for countries and firms to seek for a more comprehensive measure, including taxation policy and other schemes. Since the situation of the two countries are the same, total welfare of the two countries will display the same trend with country $x$. Therefore, taking social welfare as the major concern in this group, it is better to levy tariff on each other. 

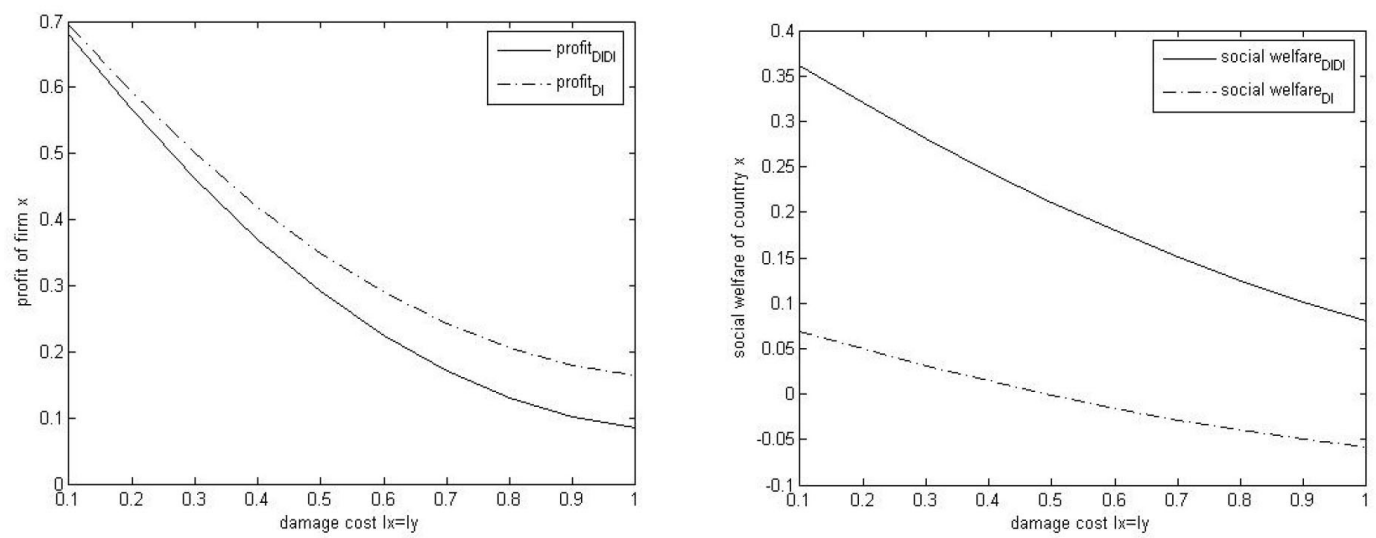

Figure 1 . The comparison of $\pi_{x}$ and $R_{x}$ between DIDI and DI scenario

\subsubsection{The Developed and Developing Country Group}

In this scenario, we consider one developing country and one developed country, so the parameter setting is no longer symmetric. We vary the damage cost of developing country $\left(l_{y}\right)$, and let the damage cost of developed country take its values of $0.25 l_{y}, 0.5 l_{y}$ and $0.75 l_{y}$ respectively. Here we set $a_{x}=1, a_{y}=0.8, c_{x}=0.3, c_{y}=0.15, d_{x}=0.3, d_{y}=0.5$. Under the ranges limited by the production quantities, we let $l_{y}$ take its values from 0.4 to 1 , which we believe that this range of values is large enough to encompass most, if not all, realistic situations.

Let us first look at firm profit comparison among DIDI, DI and DID scenario.

Obviously, with the increase of damage cost, firm profits display a downward trend, which is in accordance with the reality. To compare the three curves vertically in Figure 2, it can be seen that the optimal taxation policy for the two firms is not the same one. It also changes with the damage cost value. The cost advantage of firm $y$ is becoming more and more obvious. When the damage cost is relatively small, the optimal taxation policy for firm $x$ is the unilateral policy, which at the same time is the worst for firm $y$. But the situation changes with the increase of damage cost. When the damage cost is relatively high, the optimal taxation policy for firm $y$ is the unilateral policy, which is the worst for firm $x$. The implication is consistent with proposition 4. Under the unilateral policy, firm $y$ has no incentive to increase cost to reduce emission. The huge cost advantage will benefit her own profit and hurt the competitor's profit significantly.

For country $x$, if damage cost is relatively low, it is better to maintain the status quo and to prevent country $y$ from implementing taxation policy. While if damage cost is relatively high, country $y$ 's levying carbon tax will benefit firm $x$. In addition, if damage cost is extremely high, the developed country may subsidize her firms to increase domestic production quantity and 
restrict import quantity. This might be the reason why firm $x$ 's profit in scenario DID displays a rising trend after dropping.
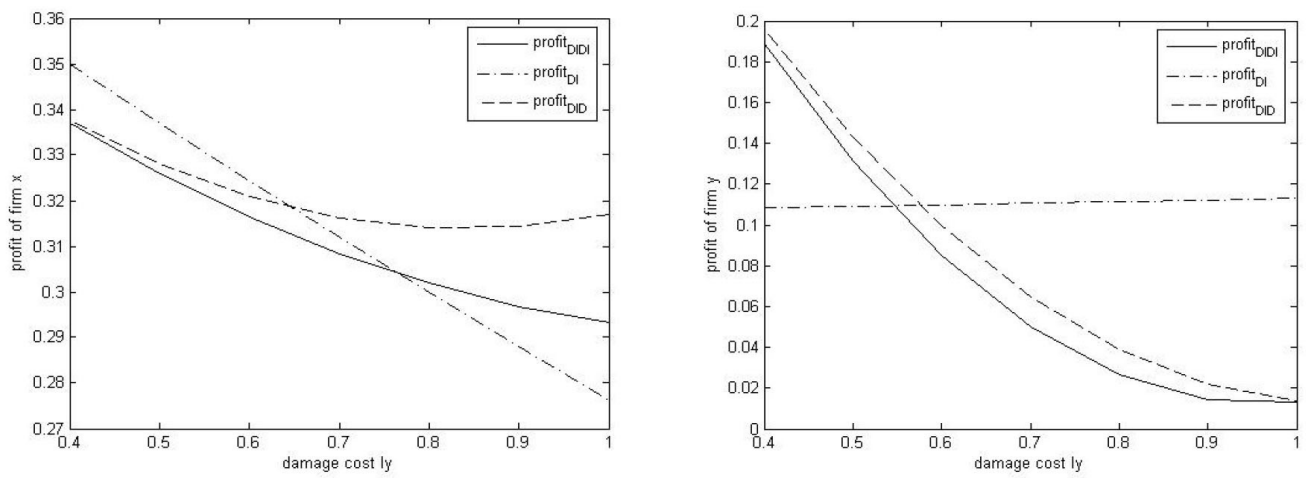

Figure 2. The comparison of $\pi_{x}$ and $\pi_{y}$ between scenario DIDI, DI and DID $\left(l_{x}=0.25 l_{y}\right)$

For the settings that $l_{x}=0.5 l_{y}$ and $l_{x}=0.75 l_{y}$, firm profit of the three scenarios display the similar trend. It can be found that for firm $y$, there is almost no difference among the three settings, whereas for firm $x$, the falling speed of profit is increasing in $l_{x}$ obviously. And the profit in the first setting $\left(l_{x}=0.25 l_{y}\right)$ is higher than that of another two settings, i.e., a more environmental-friendly firm has a competitive advantage over others.

Next we investigate the social welfare comparison among DIDI, DI and DID scenario.

From Figures 3 and 4, we notice that for all parameter values, social welfare of the two countries could reach their optimal value in the same taxation policy, which is the DID taxation policy. For country $y$, there is almost no difference among the three settings, so we just focus on the comparison of country $x$.

Figure 3 indicates that the developed country's social welfare in DID scenario is increasing in $l_{y}$, which indicates that developed country's environmental advantage contributes more to social welfare.
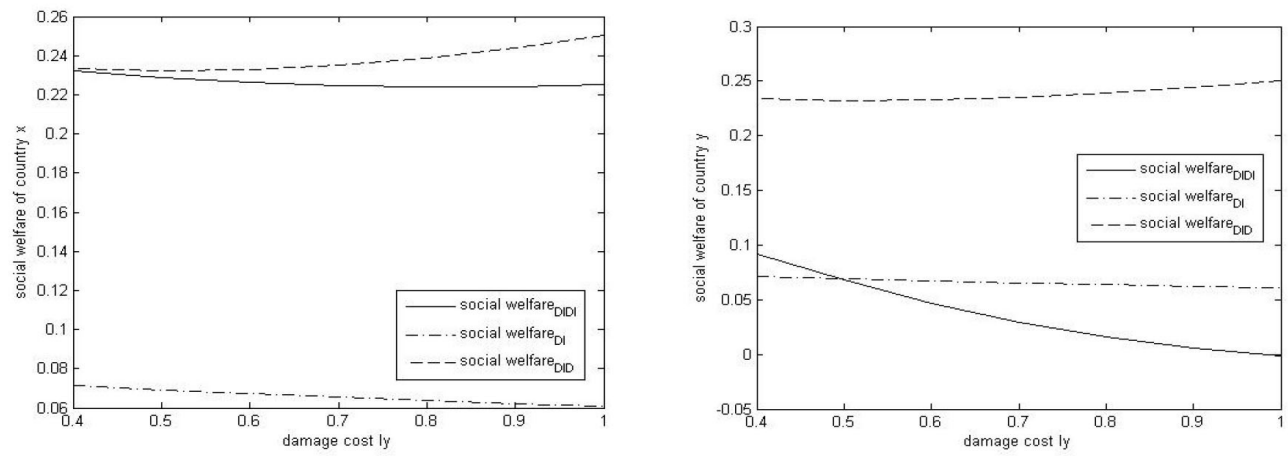

Figure 3. The comparison of $R_{x}$ and $R_{y}$ between scenario DIDI, DI and DID $\left(l_{x}=0.25 l_{y}\right)$ 

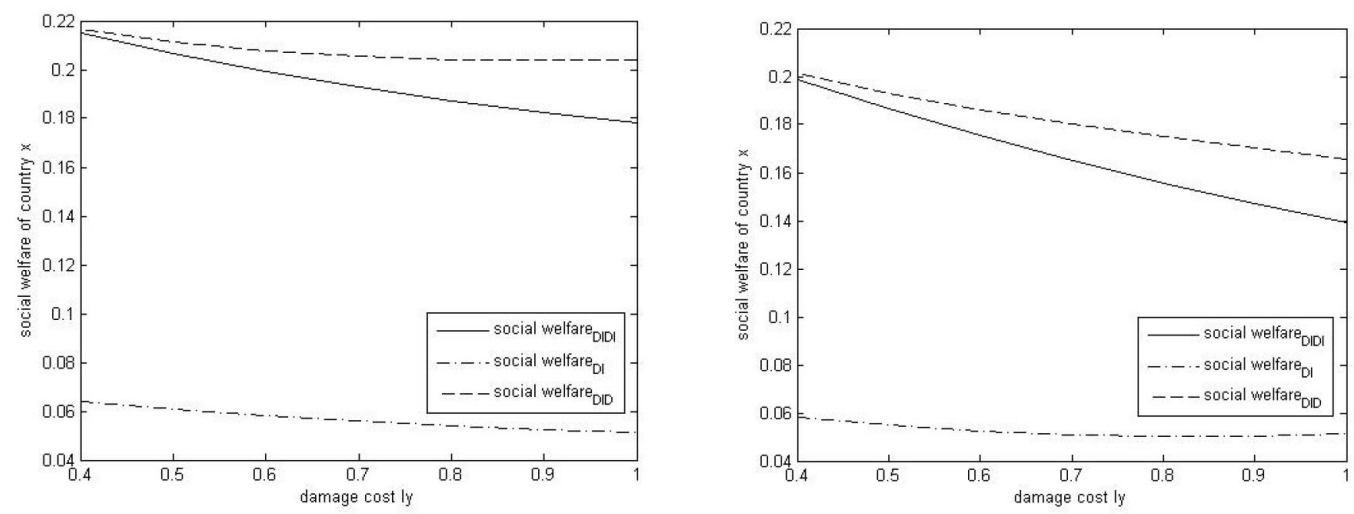

Figure 4. The comparison of $R_{x}$ between scenario DIDI, DI and DID $\left(l_{x}=0.5 l_{y}\right.$ and $\left.l_{x}=0.75 l_{y}\right)$

Taking Figure 3 and Figure 4 together to analyze, it can be found that with the increasing of $l_{x}$ the gap between the three taxation scenarios narrows down, which means that the environmental advantage is smaller. For country $x$, the falling speed of social welfare is increasing in $l_{x}$ obviously. It can also be found that country $y^{\prime}$ s any decision of levying tax will increase developed country's social welfare to a large extent, so an appropriate use of taxation policy of country $y$ will be accepted by both countries.

In our analysis in the first part of section 4, the overall impact of taxation policy on social welfare depends on the relative values of $a_{y}$ and $c_{y}+2 l_{y} d_{y}$. From the numerical results we could see that for developed country, the positive effect of any bilateral taxation policy outweighs the negative. For developing countries, appropriate use of carbon tax is always better, while the use of carbon tariff should be further investigated.

According to our analysis above, we derive the following conclusions:

For two developed countries with carbon tax, levying tariff on each other will hurt their firms' profit but benefit their social welfare. For a developing country, if she is conducting international trade with a developed country with comprehensive carbon taxation policy, a better choice for her own social welfare is to start to levy carbon tax on domestic firms only.

\section{Conclusions and Future Research}

We have derived the Stackelberg equilibrium decision made by the two countries and two firms by four taxation modeling. In the first part of the paper, the corresponding optimal output decisions of firms and optimal tax rates of countries are obtained. Our analyses reveal that the demand of unstable market is heavily affected by environmental damage level. Therefore, 
great attention should be paid to environmental issues in order to stabilize market. Results also indicate that carbon tariff is a policy-oriented tax and carbon tax is a market-oriented one. The main purpose of carbon tariff is to protect domestic firms while the carbon tax is to force firms to control emission. And unilateral taxation policy cannot effectively reduce emission. These results are the mainly contribution of our paper, which are also of great significance both in theoretical analysis and practical application.

In the second part of the research, we compared the different models to indicate the effect of taxation policy on countries and firms. During the comparison, we take real-economic situation into consideration and categorize the problem into two groups. One is the developeddeveloped country group and the other is the developed-developing country group. The optimal decisions for the two groups are discussed, respectively. The comparative analyses reveal that the taxation policy adopted mostly depends on the international standing and competitiveness of the two countries. A more comprehensive carbon taxation policy may benefit developed countries more when they trade with each other under current environment condition. And a basic carbon taxation policy will suit developing countries more. It is a better choice for developing countries to take measures, such as carbon tax on domestic firms dealing with the pressure from developed countries. Results and conclusions in this part can give decision makers some useful suggestions and instructions.

Several extensions to this study are possible. Further research with the random demand is worth studying, which may make the results more correspond with reality. Besides, taking other emission-reduction schemes into consideration may improve the whole model. Moreover, our research is carried out under symmetric information. Therefore, investigating the optimal decision for countries and firms under asymmetric information is also a worthy work in the future.

\section{Acknowledgement}

This research is supported in part by the National Natural Sciences foundation of China under Grant 71071134, 71202114, Natural Science Foundation of Hebei Province, China (No. G2013203169), Foundation of High-level personnel projects in Hebei province (C201400157), Independent Innovation and Achievement Transformation Special Fund of Shandong Province (2014ZZCX03302) and Shanghai Industry-University-Research Institute Collaboration Fund of China (HU-CXY-2014-014).

\section{References}

Avi-Yonah, R., \& Uhlmann, D. (2009). Combating global climate change: Why a carbon tax is a better response to global warming than cap and trade. Stanford Environmental Law Journal, 28, 35-49. 
Burniaux, J.M., Chateau, J., \& Duval, R. (2013). Is there a case for carbon-based border tax adjustment? An applied general equilibrium analysis. Applied Economics, 45, 2231-2240. http://dx.doi.org/10.1080/00036846.2012.659346

Dong, Y., \& Walley, J. (2012). How large are the impacts of carbon motivated border tax adjustments? Climate Change Economics, 3,1-37. http://dx.doi.org/10.1142/S20100007812500017

Eyland, T., \& Zaccour, G. (2012). Strategic effects of a border tax adjustment. International Game Theory Review, 14, 1-22. http://dx.doi.org/10.1142/S0219198912500168

Eyland, T., \& Zaccour, G. (2014). Carbon tariffs and cooperative outcomes. Energy policy, 65, 718-728. http://dx.doi.org/10.1016/j.enpol.2013.10.043

He, Y., Wang, L., \& Wang, J. (2012). Cap-and-trade vs. carbon taxes: A quantitative comparison from a generation expansion planning perspective. Computers \& Industrial Engineering, 63, 708-716. http://dx.doi.org/10.1016/j.cie.2011.10.005

Hübler, M. (2012). Carbon tariffs on Chinese exports: Emissions reduction, threat, or farce? Energy Policy, 50, 315-327. http://dx.doi.org/10.1016/j.enpol.2012.07.025

Lin, B., \& Li, X. (2011). The effect of carbon tax on per capita CO2 emissions. Energy policy, 39, 5137-5146. http://dx.doi.org/10.1016/j.enpol.2011.05.050

Song, J., \& Leng, M. (2012). Analysis of the single-period problem under carbon emissions policies. In Choi S.M. (Ed.), Handbook of Newsvendor Problems. Springer New York, 297-313. http://dx.doi.org/10.1007/978-1-4614-3600-3_13

Springmann, M. (2012). A look inwards: Carbon tariffs versus internal improvements in emissions-trading systems. Energy Economics, 34, 228-239.

http://dx.doi.org/10.1016/j.eneco.2012.08.039

Wang, M., Wang, M., Dang, C., \& Wang, S.(2012). The effects of carbon tariff on imports into the us: a game analysis. Advances in Information Sciences \& Service Sciences, 4, 263-271. http://dx.doi.org/10.4156/aiss.vol4.issue6.30

Yu, H. (2012). The Likelihood of Levy Carbon Tariff and China's Corresponding Strategy, Proc. of the 2012 3rd International Conference on E-Business and E-Government-Volume 03, IEEE Computer Society, 1082-1084.

Journal of Industrial Engineering and Management, 2015 (www.jiem.org)

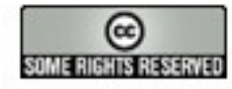

Article's contents are provided on a Attribution-Non Commercial 3.0 Creative commons license. Readers are allowed to copy, distribute and communicate article's contents, provided the author's and Journal of Industrial Engineering and Management's names are included. It must not be used for commercial purposes. To see the complete license contents, please visit http://creativecommons.org/licenses/by-nc/3.0/. 